\title{
"0 júri da morte" (1886), crônica de Ciro de Azevedo
}

\author{
Apresentação e notas de:
}

Leonardo Mendes

Universidade do Estado do Rio de Janeiro, Brasil

https://orcid.org/0000-0002-8318-3759

\section{Apresentação}

A crônica "O júri da morte", de Ciro de Azevedo (1858-1926), foi publicada na revista $A$ Semana, no Rio de Janeiro, a 16 de janeiro de 1886, pouco mais de um mês após a morte do escritor naturalista francês Louis Marie Desprez (1861-1885), autor de um estudo pioneiro da estética, L'Évolution naturaliste (1884), e do romance Autour d'un clocher (1884), que lhe rendeu um processo por atentado ao pudor, no qual foi condenado a cumprir um mês de prisão. Desprez cumpriu a pena entre fevereiro e março de 1885, mas quando saiu da cadeia estava com os pulmões fatalmente comprometidos e morreu a 8 de dezembro. A morte do escritor causou indignação. Na França, Zola publicou um artigo de repúdio no jornal Le Figaro. No Brasil, o jovem Ciro de Azevedo usou a ocasião para defender a liberdade incondicional dos artistas e se declarar escritor naturalista, reafirmando os principais preceitos da estética como uma arte de observação dos "fatos da vida", realista e antiburguesa.

Ciro de Azevedo nasceu em Aracaju em 1858, mas mudou-se cedo para São Paulo, onde se tornou bacharel pela Faculdade de Direito, em 1882. Enquanto foi acadêmico, destacou-se pela oratória e pelos ideais abolicionistas e republicanos que desde a juventude começou a propagar em conferências e artigos na imprensa, chegando a criar o próprio jornal, O Americano, em 1881. Em 1883 foi nomeado promotor público em Rio Bonito (RJ) e lá atuou até 1885, fundou o Partido Republicano local e se notabilizou como "o advogado dos escravos". ${ }^{1}$ Por essa militância atraiu a ira das classes proprietárias. Em 1885, mudou-se para a Corte, onde trabalhou como delegado de polícia até 1886, tendo sido pioneiro na divulgação das ideias do médico italiano Cesare Lombroso (1835-1909). Em 1887, abriu escritório de advocacia no Beco das Cancelas,

1 Correio Paulistano, 17 jan. 1927, p. 2. 
e ganhou notoriedade pela defesa eloquente e bem-sucedida de acusados de assassinato e de provocar abortos.

Enquanto esteve no Rio, Ciro de Azevedo contribuiu para os principais jornais da cidade, como O Paiz e a Gazeta de Notícias. Ao lado de José do Patrocínio (1854-1905), engajou-se ativamente na campanha abolicionista, assim como nas batalhas pela República, junto a Quintino Bocaiuva (1836-1912) e Saldanha Marinho (1816-1895). No segundo aniversário da libertação dos escravos nos Ceará, em março de 1886, discursou no teatro Politeana ao lado de Joaquim Nabuco (1849-1910). ${ }^{2}$ Com Silva Jardim (1860-1891), fez campanha pelo interior da província fluminense e impressionou a todos quando, num comício republicano em Paraíba do Sul, apaziguou uma multidão de monarquistas enfurecidos com o poder da palavra e da persuasão. ${ }^{3}$ Ele era tão próximo ao grupo que ascende ao poder em 1889, que sua nomeação como ministro plenipotenciário no Chile, em janeiro de 1890, foi um dos primeiros atos do Governo Provisório.

A entrada na carreira diplomática certamente o afastou do meio literário, mas o Ciro de Azevedo da crônica "O júri de morte", em 1886, no auge da campanha abolicionista, é o jovem advogado ateu, republicano e libertário, que corajosamente se declara naturalista, numa época em que isso podia significar, como no caso de Desprez, risco de morte. Entre maio e junho de 1884, ele já havia publicado seis crônicas sobre o naturalismo na Gazeta de Notícias, nas quais defendeu a grandeza de Zola e a seriedade da estética como "estudo humano" e "análise de uma sociedade". ${ }^{4}$ O naturalismo de Ciro de Azevedo pode ser detectado em contos publicados nos jornais e que foram parcialmente reunidos nos volumes Um ano de imprensa (1887) e Alma dorida (1904), formando um corpus naturalista brasileiro esquecido. A crônica traz novos atores do debate sobre o naturalismo no Brasil e comprova que o movimento foi mais extenso e complexo do que dá a entender a historiografia tradicional.

“0 Júri da morte”, A Semana, v. II, n. 55, Rio de Janeiro, 16 de janeiro de 1886, p. 18.

Em mês do ano recém-morto contaram jornais de França, o processo contra Louis Desprez, um rapazola de talento, autor de um belo estudo sobre escritores naturalistas. ${ }^{5}$

Acusado de ofensa à moral pública, por haver desenhado em romance de sua lavra fatos da vida, sem os arrebiques dos literatos à Vatteau $[$ sic $],{ }^{6}$ engendrando coisas boas e mundos de ideal

\footnotetext{
2 Gazeta de Notícias, 25 mar. 1886, p. 2

3 Correio Paulistano, 17 jan. 1927, p. 2.

${ }^{4}$ Gazeta de Notícias, 01 maio 1884, p. 1.

${ }^{5}$ Louis Desprez (1861-1885), escritor naturalista francês, morto de tuberculose aos 24 anos, produziu três obras dedicadas ao naturalismo, que defendida arduamente - uma coletânea de versos (La Locomotive, 1883) e um romance (Autour d'un clocher, 1884), escritos em colaboração com Henry Fèvre (1864-1937), e o ensaio crítico L'Évolution naturaliste, 1884), contendo seis estudos dedicados a Gustave Flaubert, aos irmãos Goncourt, a Alphonse Daudet, a Émile Zola, ao teatro e aos poetas (BECKER e DUFIEF, 2017, vol. 1, p. 296-298).

${ }^{6}$ Provável referência ao pintor francês Antoine Watteau (1684-1721) e ao gênero de pintura por ele criado, as fêtes galantes, representando a vida frívola da aristocracia francesa em suas reuniões ao ar livre, como no célebre quadro Embarquement por Cythère.
} 
ventura e pureza, antes narrando o observado com o colorido honesto da realidade, o desventurado autor viu-se condenado por meia dúzia de pantafaçudos burgueses, enfardados na tolice a mais profunda, a mais besta possível.

A ira da banalidade, representada por um grupo de microcéfalos, atirou-se sobre a mísera criança, e, em nome da lei, prendeu-a em cárcere de ladrões e bêbados.

Fraco de corpo, de uma saúde delicada e carecedora de mimos, o talentoso mancebo ganhou em pouco afecção pulmonar que o levou à cova.

E deu-se em Paris o que venho contando; e ainda naquela terra de liberdade se mata gente por escrever o visto e ouvido.

Compreendo agora a cólera desenfreada, o ódio bíblico, demoníaco, publicado por Zola, no seu esplendido grito de combate - Mes haines. ${ }^{7}$ É justa aquela fúria contra a indiferença lorpa dos bem jantados e dos peraltas sem brio acusando a literatura de mister de ocioso; é cabida a cólera relampejante contra a virtude frágil e beata que se arreceia da verdade escrita com intuitos educadores, obra de talento orientado, nota de temperamento literário.

Saracoteie de gáudio báquico a virtude social simbolizada pelos juízes de Desprez; morreu na enxovia o ousado cavaleiro das letras, infanção ${ }^{8}$ de boa nobreza em desperdício de coragem.

Mande a moral iluminar as ruas e em véus de estrelejada e rósea gaze envolver o Arco do Triunfo, não há muito adereçado de crepe por morte de Victor Hugo. ${ }^{9}$

Grande tolice humana, imortal adversária de todas as manifestações do talento, vamos! escancara a boca no seu sorriso mais expressivo, e goza, bêbada; empunha o tirso ${ }^{10}$ e dança sobre a cova dessa criança valente que se afundiu na morte por tua culpa.

E como pôde caber na escuridão da cova a aurora inteira de uma inteligência ousada? E como não explodiu em louca ira, de sob a terra, esse outro vulcão, o cérebro do romancista e do crítico?

Está contente a Moral; as enodoadas vestes limpou zelosa, e Deus, esse produto da covardia e da ignorância humana, deve agora sorrir de satisfeito, alisando a longa e prateada barba.

\footnotetext{
7 Coletânea de artigos de crítica literária publicada por Zola em 1866, portanto, no início de sua carreira, reunindo textos originalmente veiculados em grande parte pelo jornal Le Salut public de Lyon, entre janeiro e dezembro de 1865. Entre outros, figuram artigos dedicados ao romance Germinie Lacerteux, dos irmãos Goncourt, aos moralistas franceses, a Hippolyte Taine. Num artigo dedicado a Proudhon e Courbet, o escritor formula sua conhecida definição de obra de arte: "um canto da natureza visto através de um temperamento" (BECKER et al., 1993, p. 259-260).

8 Título de nobreza inferior ao de fidalgo ou de rico-homem.

${ }^{9}$ Victor Hugo havia falecido em 22 de maio de 1885, e seu funeral teve as honras concedidas a um chefe de Estado. Antes de entrar para a glória ao ser enterrado no Panteão de Paris, seguido por um cortejo de mais de 1 milhão de pessoas, seu corpo havia ficado exposto durante 0 dia inteiro sob o Arco do Triunfo, que havia sido coberto de tecido preto (LE FIGARO. 21/5/2015, on-line. https://www.lefigaro.fr/histoire/archives/2015/05/21/26010-20150521ARTFIG00312-le-22-mai-1885-victor-hugo-meurt-a-paris.php)

${ }^{10}$ Bastão enfeitado com hera e ramos de videira, e rematado em forma de pinha, insígnia de Baco e das bacantes.
} 
Eu sinto dentro de mim o tumultuar do ódio, e sinto a instintiva necessidade de injuriar esses assassinos, que, em nome de uma coletividade, em nome de um povo heroico e inteligente, bondoso e tradicionalmente bravo, atiram com uma criança a uma enxovia imunda e deixam-na morrer... e deixam-na morrer!...

Desprez teve o heroísmo de não suplicar o perdão do presidente da república, por desconhecer capacidade nos juízes, justiça no veredictum, legitimidade no processo.

Desgraçada virtude social essa que vinga injurias por meio de crueza de burgueses atoleimados!

O único tribunal para o livro é o público ledor; o único juiz da obra do talento é o consumidor literário ou científico.

Se o livro não presta; se a preocupação luxuriosa foi a determinante do trabalho; se a ânsia do êxito rebuscou motivos de sensualidade e trouxe a gama inteira do nu e do indecente; despreze o público essa mercadoria avariada, varra-a do mercado pelo seu desprezo; deixe morrer à míngua o escritor corrompido ou estulto.

Mas quando a produção emana de um talento honesto, observador e leal; quando a vida é agarrada em flagrante pelo literato, e a natureza transmitida pelo prisma do seu temperamento, trazendo o cunho da sua compleição mental, guarde o público respeito ao produtor, embora rejeite o produto.

Arvorar uns tantos idiotas em guardas da honra social; atirar esses gafeiros contra um livro, cujo valor eles não podem apreçar; criar penas contra o literato, condená-lo à cadeia, e tudo isso em nome da lei, com o auxílio da força, com o prestígio do direito, é praticar uma infâmia desmarcada. ${ }^{11}$

Sou naturalista convencido, por estudo e não por moda.

Ganhei na meditação e na leitura compassada de tudo o que se tem escrito, romance e crítica, sobre naturalismo, o ardimento para essa confissão, já anteriormente lançada em artigo, na Gazeta de Notícias, e que me vai agora trazer novos ódios. E estimando a literatura como o partidário a política e o crente a sua fé, atiro o grito de assanhada cólera contra essa infâmia de um assassinato legal.

Dou remate ao meu indignado protesto reproduzindo as palavras de Zola, colhidas em um jornal desta Corte: "Nesse momento não quero mais saber se nesse assassinato houve um tribunal, jurados, um prefeito de polícia; sinto apenas necessidade invencível de bradar: - Aqueles que mataram essa criança são uns miseráveis!”

Corte, 4 de janeiro de 1886.

${ }_{11}$ Desmedida, excessiva. 


\section{REFERÊNCIAS}

BECKER, Colette; DUFIEF, Pierre-Jean (Eds.). Dictionnaire des naturalismes. 2 v. Paris : Honoré Chapion, 2017.

BECKER, Colette et al. Dictionnaire d'Émile Zola : sa vie, son œuvre, son époque suivi du Dictionnaire des Rougon-Macquart. Paris: Robert Laffont, 1993. 